\title{
Osteopenia in Growth Hormone (GH) Deficient Children: Effect of Growth Hormone Treatment
}

\author{
Giuseppe Saggese, Giampiero Igli Baroncelli, Silvano Bertelloni and Giovanni Federico \\ Chair of Preventive Pediatrics, Department of Pediatrics, University of Pisa, Pisa, Italy
}

\section{Introduction}

Children with growth hormone (GH) deficiency have osteopenia partly because of delayed bone maturation (1). Studies on GH treated patients have given contrasting results on the recovery of bone mineralization (1-3). We investigated bone density before and during recombinant human (rh) $\mathrm{GH}$ treatment in $\mathrm{GH}$ deficient children.

\section{Patients and Methods}

Twenty-six prepubertal children (14 M, 12 $\mathrm{F}$; age 6.5-10.7 years, bone age $5.6 \pm 1.7$ years, height-SD score (SDS) $-3.0 \pm 0.5$, growth velocity $2.7 \pm 0.8 \mathrm{~cm} / \mathrm{y}$ ) with isolated idiopathic $\mathrm{GH}$ deficiency were studied. We evaluated bone mineral density (BMD, $\mathrm{g} / \mathrm{cm}^{2}$ ) by single photon absorptiometry (Norland Corp., mod. 2783) at the distal one-third of the nondominant radius before and at 12 and 24 months of rhGH administration (0.6 IU/kg/weekly, sc). Results were expressed as SDS (mean \pm SD) in comparison with our gender-and age-matched reference values for chronologic and bone ages (4).

Correspondence: Dr. Giuseppe Saggese, Department of Pediatrics, University of Pisa, Via Roma, 35, I-56125, Pisa Italy

\section{Results}

Before rhGH, all patients had a significant reduction of $\mathrm{BMD}$ for both chronological age and bone age (Table). During treatment, growth velocity (12 months: $7.5 \pm 1.7 \mathrm{~cm} / \mathrm{y} ; 24$ months: $5.2 \pm 1.8 \mathrm{~cm} / \mathrm{y}, \mathrm{P}<0.001$ vs. pretreatment values) and BMD (Table) significantly increased in all patients. After 12 months, about $50 \%$ of children had normal BMD for BA. After 24 months, normal BMD for CA and BA was found in 8 out of 9 children (89\%).

Table Bone mineral density before and during rhGH therapy

\begin{tabular}{lccc} 
& 0 & 12 mon & 24 mon $^{\circ}$ \\
\cline { 2 - 4 } BMD-CA, SDS & $-1.2 \pm 0.6^{*}$ & $-0.5 \pm 0.3^{\wedge}$ & $0.2 \pm 0.2^{\wedge}$ \\
BMD-BA, SDS & $-0.7 \pm 0.3^{* *}$ & $-0.2 \pm 0.02 \#$ & $-0.1 \pm 0.02 \#$ \\
\hline
\end{tabular}

$\mathrm{CA}$ : chronologic age; $\mathrm{BA}:$ bone age; ${ }^{*} \mathrm{P}<0.01,{ }^{* *} \mathrm{P}<0.02$ vs reference values.

${ }^{\circ} \mathrm{n}=9 ;{ }^{\wedge} \mathrm{P}<0.01, \# \mathrm{P}<0.02$ vs pretreatment values.

\section{Discussion}

We demonstrated that GH deficient children have reduced BMD. Delayed bone maturation does not completely account for the reduced BMD. Thus, GH deficient children are really osteopenic. Therapy with $\mathrm{rhGH}$ was able to improve BMD which reached the normal range in $89 \%$ of the patients after 24 months of therapy. The reduced BMD in GH deficient adults results more likely from a deficient build-up of the bone mass than from 
a premature bone loss (5). So, the beneficial effect of rhGH therapy on BMD in GH deficient children suggests that this treatment might lead to the attainment of the peak of bone mass, which is one of the most important factor in preventing adult osteoporosis (6).

\section{References}

1. Saggese G, Baroncelli GI, Bertelloni S, Cinquanta L, Di Nero G. Effects of longterm treatment with growth hormone on bone and mineral metabolism in children with growth hormone deficiency. J Pediatr 1993; 122: 37-45.

2. Shore RM, Chesney RW, Mazess RB, Rose PG, Bargman GJ. Bone mineral status in growth hormone deficiency. J Pediatr 1980; 96: 393-6.

3. Zamboni G, Antoniazzi F, Radetti G,
Musumesi C, Tatò L. Effects of two different regimens of recombinant human growth hormone therapy on the bone mineral density of patients with growth hormone deficiency. $\mathrm{J}$ Pediatr 1991; 119: 483-5.

4. Saggese G, Federico G, Ghirri P, Cipriani J, Bertelloni S, Baroncelli GI. Densitometria ossea in età pediatrica. Valori normali tra 2 e 19 anni. Primi dati italiani. Minerva Pediatr 1986; 38: 545-51.

5. Kaufman JM, Taelman P, Vermeulen A. Vandeweghe M. Bone mineral status in growth hormone-deficient males with isolated and multiple pituitary deficiencies of childhood onset. J Clin Endocrinol Metab 1992; 74: 118-23.

6. Christiansen C. Consensus development conference on osteoporosis. Am J Med 1991; 5B: 1S-68S. 